\title{
Considerações Acerca de Teses Recentes sobre o Mundo Rural Brasileiro
}

Lauro Mattei ${ }^{1}$

Resumo: Este artigo apresenta uma análise crítica das sete teses sobre o rural brasileiro. Depois de expor cada uma das referidas teses é feita uma análise crítica detalhada mostrando as inconsistências e até mesmo as contradições dessas teses. Finalmente, são apresentadas algumas considerações gerais, ressaltando-se a importância desse debate, porém entendendo que o mesmo deveria ser feito de acordo com a complexa realidade rural brasileira e sem a exclusão de determinados segmentos sociais.

Palavras-chaves: Brasil, rural, teses, críticas.

Abstract: This article presents a critical analysis of seven theses about the Brazilian rural area. In the beginning we explain these entire theses, and after then we wrote a very critical analysis that point out some inconsistent and contradictions that we saw in these theses. Finally, we present some general considerations highlighting the importance of this debate, but with the comprehension that this debate should be done according to the rural complexity situation, and without any exclusion of social segments that live in the rural area.

Key-words: Brazil, rural, thesis, critics.

Classificação JEL: Q180.

1. Professor do curso de Economia e do programa de Pós-graduação em Administração, ambos da UFSC. Doutor em Economia pela Unicamp e Pós-doutor em Economia pela Universidade de Oxford.E-mail: 1.mattei@ufsc.br 


\section{Introdução}

As análises dos processos sociais, suas espacialidades e suas diversidades devem considerar também a temporalidade histórica dos mesmos. No caso específico do mundo rural brasileiro, não se pode relegar ao esquecimento sua trajetória histórica e suas implicações contemporâneas em diversas esferas da vida humana e do próprio meio ambiente. Assim, observa-se que, em termos das relações de trabalho, ainda permanecem no espaço rural brasileiro resquícios da escravidão. Tanto é assim que apenas no ano de 2013 mais de duas mil pessoas foram retiradas, pelo Ministério do Trabalho e do Emprego, da condição de escravidão em que se encontravam quando exerciam atividades laborais no ramo agropecuário.

Outro fator determinante na trajetória histórica do desenvolvimento rural brasileiro diz respeito ao processo colonizador que dá coesão a uma trajetória contínua que liga a sociedade agrária (passado) à sociedade contemporânea (presente). Em grande medida, o elo dessa continuidade relaciona-se à forma de exploração e expropriação dos recursos naturais. É neste contexto que a questão da terra, em particular da propriedade da terra, foi e continua sendo um tema relevante no debate sobre o desenvolvimento do país, o qual permanece no topo da lista de nações com os maiores índices de concentração de terra no mundo.
Historicamente, a vida material do país, em especial no meio rural, foi moldada por um processo colonizador cuja função econômica se restringia à produção de excedentes para exportação. Isto conformou um sistema produtivo assentado na grande propriedade da terra, na monocultura em larga escala e no trabalho escravo. Hoje se observa que o sistema produtivo dominante continua amparado numa lógica muito semelhante (grandes propriedades de terra, propriedade privada dos demais meios de produção, cultivo monocultor em larga escala etc.), porém encontrando no trabalho livre seu substrato de acumulação e de valorização. Isto leva as explorações agrícolas, com as características antes mencionadas, a desempenhar no presente suas funções econômicas de forma mais consistente, tornando-as mais relevantes no conjunto da produção do país a partir de uma visão meramente econômica.

Esse movimento moldou uma concepção interpretativa sobre o "mundo rural brasileiro" que associava mecanicamente o desempenho econômico de um determinado setor presente no espaço rural à ideia de eficiência, ao mesmo tempo em que caracterizava todos os demais setores e a própria diversidade rural como sinônimo de um atraso que precisava ser superado. Com isso, desconsiderava-se a existência de uma realidade multifacetária que torna o referido espaço um patrimônio indispensável ao desen- 
volvimento do conjunto da sociedade brasileira contemporânea. São essas concepções que, de alguma forma, estão presentes nos debates atuais sobre a ruralidade brasileira.

A visão tradicional sempre considerou e interpretou o meio rural brasileiro apenas como espaço de produção agrícola, procurando mensurar a evolução do desenvolvimento unicamente a partir de critérios e de indicadores de desempenho econômico setorial da agricultura nos mercados. Assim, mesmo com o enorme êxito obtido pela "Revolução Verde" em termos de expansão da produção agropecuária, fica cada vez mais evidente o equívoco dessas interpretações que sistematicamente rebaixaram as funções do espaço rural.

Recentemente parte dessa trajetória interpretativa reapareceu nos debates e proposições autodenominadas de "novas teses" sobre o rural brasileiro. Buainain et al. (2013, p. 120), em artigo intitulado "Sete teses sobre o mundo rural brasileiro" concluem o trabalho esperando "que o conjunto de teses aqui submetido ao debate possa contribuir para uma fértil e plural discussão, a qual aponte rumos mais robustos para a história agrária brasileira". Todavia esta expectativa é refutada em várias passagens do próprio artigo quando se afirma que a outras interpretações "sequer cabe menção", uma vez que seus argumentos sobre outras formas de produzir "são estapafúrdios", "causam náuseas", etc. Além disso, afirma-se que todas as proposições apresentadas têm um inquestionável lastro empírico para sustentá-las. Ou seja, o debate somente será "fértil e plural" se ficar restrito aos parâmetros analíticos e aos argumentos propostos pelos autores das "7 teses".

Com o objetivo de fugir desses "argumentos de autoridade" e de efetivamente contribuir com o debate atual, elaborou-se o presente trabalho. Nele, busca-se dialogar com as "teses" antes mencionadas numa perspectiva crítica, destacando alguns pontos chaves para o entendimento dessas proposições e de suas contradições. Para tanto, o artigo está organizado em mais três seções, além desta breve introdução. Na pri- meira delas é feito um sumário dos elementos centrais apontados pelos autores do artigo acima mencionado. A segunda seção apresenta uma análise crítica sobre tais proposições, buscando uma contraposição a essas teses com outros elementos interpretativos e dados empíricos. A terceira seção apresenta as considerações finais do estudo, procurando sistematizar as principais discordâncias interpretativas em relação ao trabalho analisado.

\section{Elementos centrais do documento "sete teses sobre o mundo rural brasileiro"}

$\mathrm{O}$ artigo antes mencionado oferece uma interpretação sobre o mundo rural brasileiro contemporâneo com o intuito de analisar fatos e definir algumas proposições que, segundo os próprios autores, poderiam esclarecer a "situação atual e apontar as tendências do desenvolvimento da agropecuária e das regiões rurais brasileiras" (Buainain et al., 2013, p. 105). Obviamente que grande parte dessa leitura é feita dentro da tradição e dos marcos analíticos já mencionados na introdução.

Assim, parte-se inicialmente de uma interpretação da trajetória da agricultura nos últimos 50 anos com o objetivo de se entender "o estado atual das atividades agropecuárias e de alguns aspectos da vida social rural, além de apontar algumas de suas tendências futuras" (IBID, p. 107). Aqui já aparece uma particularidade analítica do trabalho quando se correlaciona linearmente o desenvolvimento da agricultura com o desenvolvimento das regiões rurais e, mais ainda, quando se discute apenas alguns aspectos sociais rurais, tema que em uma análise economicista obviamente teria de ser secundarizado.

A análise segue com o estabelecimento de um pressuposto relevante: as proposições intituladas de "7 teses" ficam subordinadas a uma seção inicial que explica três processos sociais. Sem isso, os próprios autores reconhecem que essas teses se tornariam "ilógicas ou inconsistentes". Ou seja, 
são as premissas analíticas que fundamentam as teses posteriores, as quais revelam, segundo os autores, um novo período do desenvolvimento das atividades agropecuárias brasileiras. Este pressuposto, na verdade, enuncia lacunas do estudo, uma vez que em diversas passagens tem-se a interpretação de fenômenos que não são semelhantes, mas que são tratados como se o fossem. Por exemplo, é bem diferente se falar de desenvolvimento da agricultura e de desenvolvimento rural; ou então falar de desenvolvimento das atividades agropecuárias e de desenvolvimento das regiões rurais, mesmo sabendo-se das conexões existentes ambas. Essas e outras questões serão exploradas na seção específica sobre a análise crítica do estudo em epígrafe.

Os processos sociais antes referidos são analisados a partir de três dimensões centrais: a temporalidade histórica; os grupos e atores sociais envolvidos; e os elementos decisivos que conformaram as transformações em análise. Essa definição analítica faz as interpretações retrocederem ao período inicial do pós-guerra, quando tem início a formação, segundo os autores, de uma agricultura capitalista no Brasil.

Do ponto de vista temporal (quando), os autores partem acertadamente da década de 1960 para mostrar que a modernização agrícola se assentou nos programas de pesquisa e extensão rural públicos e na disponibilidade de crédito rural subsidiado, mesmo que não dito que esses volumosos recursos foram subsidiados por toda sociedade. Embora reconheçam o caráter contraditório desse processo, os autores minimizam seus efeitos, especialmente em termos sociais e ambientais.

Quanto aos autores sociais (quem) que promoveram o processo de mudanças, afirma-se textualmente que "a investigação sobre que grupo de produtores foram atraídos para processo de expansão ainda não foi realizada e, assim, sabe-se apenas episodicamente sobre as responsabilidades sociais (e produtivas) dos diversos atores" (IBID, p. 108). Esta afirmação, na verdade, pretende rejeitar teses fartamente discutidas na década de 1980 que comprovaram o processo conservador da modernização da agricultura brasileira². No lugar daquelas, são oferecidas explicações bastante limitadas, como quase querendo explicar todo esse processo apenas a partir do movimento migratório dos agricultores sulistas em direção às novas fronteiras agrícolas do país. Não negamos a existência desse movimento (que conhecemos muito bem até mesmo por ser parte existencial dele), mas não podemos escamotear o papel decisivo que o latifúndio e as velhas oligarquias rurais desempenharam durante esta fase histórica do país.

Quanto aos fatos que "desencadearam a intensificação tecnológica e produtiva que catapultou as atividades agropecuárias às alturas" (IBID, p. 108), os autores afirmam que eles são pouco conhecidos na literatura. Para tanto, oferecem como explicações elucidativas as mudanças institucionais realizadas durante a década de 1990, as quais "corrigiram parte dos bloqueios existentes, tendo promovido a estabilização monetária e promovido um esforço de reorganização do Estado e suas políticas visando o desenvolvimento agrícola" (IBID, p. 108-109). Esse assunto será retomado posteriormente em uma das teses quando diversas contradições em relação a esta afirmativa se sobressaem no próprio texto. Além disso, menciona-se a expansão das importações chineses da soja como outro fator relevante do processo de intensificação tecnológica. Ora, não subestimaremos o boom de commodities existentes em escala mundial nos últimos anos - do qual o Brasil se aproveitou -, mas alertamos sobre a necessidade de se ponderar que esse processo fortemente impulsionado por razões comerciais produz limitados efeitos sobre o tema que os autores estão querendo explicar. Voltaremos a esse ponto na crítica a uma tese específica.

Em função disso, os autores explicam que a junção benéfica de conhecimento tecnológico, agricultores preparados e uma ordem político-institucional adequada promoveram as condições ideais para que o "processo modernizante"

2. Vide obra clássica de José Graziano da Silva: A modernização dolorosa: estrutura agrária, fronteira agrícola e trabalhadores rurais no Brasil. Zahar editores, 1982. 
se espalhasse por todo o território, com impactos visíveis em todas as regiões do país.

Dentre esses impactos no Brasil rural, os autores destacam três deles. O primeiro é que a expansão produtiva recente se baseia em padrões técnicos e organizacionais que modificam os condicionantes e a dinâmica das atividades agropecuárias, fato que provoca, segundo os autores, uma analogia com a expansão ocorrida nos EUA no pós-guerra. O outro impacto reconhecido pelos autores é que esse padrão técnico se acentua em ambientes diferenciados, conformando uma heterogeneidade estrutural. Finalmente, o terceiro impacto mencionado diz respeito ao crescente papel que vem sendo assumido pelas cadeias produtivas mais dinâmicas, com possíveis reflexos sobre outras cadeias em formação.

A partir dessas interpretações gerais (que também serão criticadas posteriormente), foram elencadas 7 teses correlatas, como será apresentado nesta seção. Vale destacar que muitas delas sequer podem receber o nome de teses, pois são meras interpretações ou, até mesmo, apologias a determinados temas, especialmente quando os autores se reportam à questão da tecnologia.

A primeira tese trata da nova fase do desenvolvimento agrário, sendo que os autores afirmam ter ocorrido uma mudança radical no "padrão de acumulação da agricultura". A leitura é que no passado a terra era a fonte de produção da riqueza social; por isso houve forte centralidade das questões da posse e da propriedade até os anos de 1980. Hoje são as máquinas, os equipamentos, a tecnologia e o capital humano os elementos responsáveis pela acumulação de capital. Isto porque o presente exige "gestores profissionais do capital" e um aperfeiçoamento contínuo das inovações e de expansão da produtividade. Para justificar essa tese os autores utilizam explicações relativas às exportações dos anos de 1990, bem como a expansão dos arrendamentos capitalistas. Tudo isso, segundo os autores, confirma a hegemonia da agricultura moderna em todas as regiões agrícolas do país. Na verdade, essa tese foi construída para mostrar que a terra não é mais um ativo econômico de valor determinante.
Portanto, é preciso negar o seu papel no processo produtivo, bem como a necessidade de uma reforma agrária. Esses e outros aspectos serão retomados em uma seção crítica posteriormente.

A segunda tese trata das inovações tecnológicas na agricultura, destacando-se efusivamente os impactos da revolução verde, porém sem fazer qualquer menção aos efeitos negativos desse processo nas esferas social e ambiental. Mesmo que os autores clamem por um debate mais plural, nesta tese existem muitos ataques àqueles que ousarem questionar esses posicionamentos e/ou falar em tecnologias alternativas, sendo estas qualificadas como fantasiosas e/ou utópicas. Isto seria, na visão dos autores, um conjunto de críticas que ecoariam um passado que não mais corresponde ao cotidiano da agricultura moderna. Além disso, faz-se uma apologia à EMBRAPA com instrumento dessa nova era, ao mesmo tempo em que se afirma que o posicionamento ideológico paralisou a pesquisa científica no Brasil. Exageros a parte, destaca-se desde logo que, rigorosamente, esse arrazoado de argumentos não se constitui em si mesmo uma tese.

A terceira tese procura mostrar a trajetória atual do desenvolvimento agrário, porém ficando concentrada na dicotomia econômica que revela um processo de concentração da produção que, segundo os autores, aprofunda a diferenciação social e intensifica a seletividade entre os produtores rurais. Para justificar tal tese, são utilizadas informações e interpretações dos dados do último Censo Agropecuário (2006), as quais são usadas para reafirmar um argumento já antigo de que uma pequena minoria de grandes agricultores modernizados é quem efetivamente sustenta a produção agropecuária do país. Na verdade, esta também não é uma tese, mas sim uma leitura dos dados oficiais que podem receber outras interpretações, as quais não devem ser desqualificadas - como é feito nesta parte específica do artigo - se efetivamente se quer um debate plural.

A quarta tese procura escamotear o problema agrário pelo viés economicista, ao mostrar que a terra não explica mais o crescimento da produção, uma vez que o dinamismo agrário atual é dado pelos investimentos privados e pela inten- 
sificação tecnológica. A partir daí se conclui que o tema da reforma agrária perdeu relevância, não se justificando a manutenção de uma estrutura oficial com orçamento para tal finalidade. Na verdade, esta tese não é tão nova, uma vez que há tempos ela já vem sendo defendida, pelo menos por parte de alguns dos autores que assinam o documento. Como ela está carregada de fortes sentimentos ideológicos, serão questionados seus fundamentos centrais, ao serem apresentadas outras abordagens presentes nos debates.

A quinta tese discute o papel do Estado no processo de modernização da agricultura, afirmando que atualmente são os agentes privados os principais atores do desenvolvimento (sic). Para tanto, justifica-se esses argumentos com dados relativos aos gastos públicos, sobretudo a partir da década de 1990, a qual é tomada como marco histórico do processo de mudanças. Na verdade, esse foi um período histórico de avanços expressivos do projeto neoliberal no país, especialmente nas esferas econômica e política. Por isso, os argumentos apresentados não se constituem em uma tese em si mesma, apenas em fragmentos analíticos contaminados pelos resquícios dos debates ideológicos da última década do século $\mathrm{XX}$, conforme será demonstrado na seção seguinte.

A sexta tese apresenta uma leitura sobre os resultados da "dinâmica agrícola" atual, a qual enceta uma tendência perversa em relação aos estabelecimentos rurais de menor porte econômico. Para tanto, citam-se alguns casos regionais para justificar algumas linhas interpretativas. Definitivamente não foi encontrada aqui nenhuma tese substancial, a não ser interpretações de resultados de um processo maior - já mencionado na tese geral - que podem receber múltiplas interpretações teóricas e empíricas, especialmente quando as análises não forem pautadas exclusivamente pelos viés da "produção agrícola" e pelo "economicismo" agrícola ${ }^{3}$.

3. Destaca-se a seguinte passagem: "outras possíveis teses, de cunho sociocultural, seriam igualmente relevantes, mas provavelmente seriam secundárias em relação às primeiras" (IBID, p. 110). Ou seja, a esfera econômica é quem prevalece e quem determina os rumos do desenvolvimento agrário.
A sétima tese - na verdade uma mera suposição - procura mostrar equivocadamente que os rumos do desenvolvimento rural brasileiro deverão seguir a "Via Argentina", destacando-se alguns elementos fundamentais: o esvaziamento demográfico; o predomínio da agricultura em larga escala; e a alta eficiência produtiva e tecnológica da agricultura moderna. Na verdade, esta paródia é utilizada apenas para justificar um argumento já conhecido há muito tempo de que a ação governamental para o "campo brasileiro" é equivocada, especialmente no último decênio. Obviamente que não dito explicitamente, mas porque o Estado brasileiro está gastando recursos públicos equivocadamente ao dar suporte a mais de dois milhões de estabelecimentos de agricultores familiares, os quais têm "baixa eficiência econômica".

Em síntese, podemos dizer que é possível agrupar todo esse debate em três argumentos centrais: a) não temos mais uma questão agrária relevante no contexto atual, o que torna a bandeira da reforma agrária uma luta do passado que, segundo os próprios autores, "vai se apagando"; b) a produção agropecuária do país é totalmente dominada pela agricultura moderna, a qual é determinada por um pequeno número de grandes agricultores "eficientes economicamente"; e c) a ação do Estado não é mais necessária porque este é incapaz de atender aos desafios da nova ordem, afinal os agentes privados são eficazes e não devem ser perturbados pela ação governamental.

$\mathrm{Na}$ verdade, esta trilogia serve também para fundamentar o argumento principal: confirma-se hoje a supremacia da "agricultura moderna" em relação às demais formas de agricultura do país. E foi exatamente essa supremacia que a partir dos anos de 1990 conformou um novo padrão de acumulação da riqueza agropecuária, ou seja, a partir da referida década ficou estabelecido "um divisor de águas em nossa história rural” (IBID, p. 110). Todos os demais argumentos - que em sua maioria não se conformam em teses - apenas agregam elementos a esses três pontos fundamentais do artigo, o qual faz, em muitas passagens, críti- 
cas ideológicas àqueles que não compactuam da visão ali exposta. Assim como o espelho, registra-se que em seus argumentos centrais, o artigo "7 Teses" também encontra-se contaminado por afirmações ideológicas, muitas delas amplamente conhecidas por pesquisadores e cientistas das áreas sociais e agrárias.

\section{Análise crítica sobre as autodenominadas "7 teses"}

O ponto de partida desta seção se inspira na parte final do artigo quando se espera uma discussão fértil e plural sobre a história agrária brasileira. Mesmo que ao longo de todo o texto os autores apresentem um foco muito mais concentrado na trajetória da agricultura do que propriamente na história agrária do país, ofereceremos a seguir algumas explicações distintas sobre os mesmos fenômenos abordados pelos autores, todavia sem a pretensão de desqualificar qualquer análise distinta, pois entende-se que essa é uma premissa primordial para efetivamente se ter um debate plural.

Desta forma, esta seção está organizada segundo alguns pontos centrais da crítica ao trabalho em epígrafe, sem a preocupação de ficar preso às autointituladas teses. Isto porque, como dito anteriormente, muitas delas sequer deveriam ser assim chamadas. Portanto, nossa crítica recairá sobre os argumentos centrais sintetizados ao final da seção anterior.

\subsection{A análise dos condicionantes das 7 teses}

Obviamente que toda leitura de qualquer setor de atividade econômica do Brasil atual, comparativamente aos anos de 1950 e 1960, vai verificar uma abissal diferença, fato que demonstra não ser tal comportamento privilégio de apenas um determinado setor. É claro que ocorreram distinções entre esses setores de atividades, mas o que destacamos aqui é que ocorreu uma alteração geral da trajetória econômica do país em direção à constituição de uma sociedade urbano-industrial nos últimos cinquenta anos, a qual se encontra, no momento, diante de uma nova fase de transição.

Temos acordo quanto ao ponto de partida: a modernização da agricultura iniciada com maior vigor na década de 1960. Todavia, destacamos que o tripé indissolúvel citado pelos autores ${ }^{4}$ está bastante inconsistente porque sequer se faz menção ao importante papel desempenhado pela propriedade da terra neste processo. Afinal, toda a geração da riqueza agrária do país nas décadas seguintes decorreu de uma particularidade: a enorme disponibilidade de terras férteis e de boa qualidade em praticamente todas as regiões geográficas, fator que permitiu a expansão horizontal do processo modernizante até a década de 1990. E este não é um aspecto menor no processo agrário brasileiro porque foi exatamente neste mesmo período que ocorreram os maiores índices de expansão da concentração da propriedade da terra ${ }^{5}$. Aliado a isso, deve-se reconhecer que esse processo de mudanças promoveu outra alteração significativa no mundo agrário brasileiro: a terra passou a ser um ativo de valor econômico de enormes proporções, atraindo, inclusive, investimentos de outros setores econômicos do país ${ }^{6}$. Se isto não fosse verdadeiro, deveríamos nos questionar por que o preço do hectare de terra adquiriu as proporções atuais, indicador de que a mesma continua sendo um ativo econômico de grande importância no modo de geração de riqueza, em particular da riqueza agrária do país. Negar tal fato supõe a artificialização da produ-

4. Vale recordar que os autores citam apenas o crédito rural subsidiado, a pesquisa e a extensão rural.

5. Os dados dos diversos censos Agropecuários do IBGE revelam que o Índice de Gini saiu do patamar de 0,839 em 1960 para 0,858 em 1985. Nos censos seguintes (1995-2006) esse índice manteve-se praticamente no mesmo patamar.

6. Para maiores detalhes vide obra clássica de Guilherme Delgado (1985), O capital financeiro na agricultura. Recentemente o mesmo autor publicou novo livro intitulado Do capital financeiro na agricultura à economia do agronegócio (IPEA, 2012), mostrando a transição neoliberal da modernização conservadora em direção ao agronegócio, porém sem deixar de mencionar o papel decisivo do fator 'terra' neste movimento. 
ção agrícola, uma vez que esta continua permanecendo assentada na terra, independentemente dos insumos, máquinas e equipamentos que são utilizados.

Neste mesmo ponto, chama atenção o fato que os autores, embora reconheçam, amenizam ao máximo a contradição do processo de modernização conservadora da agricultura brasileira, procurando enaltecer apenas seus resultados econômicos. Todavia, entende-se que não se deve relegar ao segundo plano os impactos extremamente negativos e já amplamente documentados pela literatura especializada nas esferas sociais e ambientais, fatos estes que colocam sérias questões sobre a sustentabilidade futura do atual modelo de desenvolvimento rural do país. Nesse aspecto, o texto é lacônico em sua totalidade, apenas deixando uma escolha em forma de questionamento na sua parte final, a qual contribuiu pouco para a tarefa de se repensar o Brasil rural.

O segundo aspecto relativo aos processos sociais agrários diz respeito à interpretação feita pelos autores em relação aos atores envolvidos no conjunto de mudanças. Talvez pretendendo desconsiderar análises clássicas sobre este tema, especialmente aquelas realizadas pelas ciências sociais, afirma-se que a investigação sobre que grupos de produtores foram atraídos pelo processo de expansão ainda não foi realizada. Mas ao mesmo tempo, nega-se a análise clássica de José Graziano da Silva, que em sua obra mostrou como parte expressiva do latifúndio tradicional brasileiro se incorporou à modernização agrícola. Seria inimaginável pensar, como fazem os autores, que este processo foi motivado apenas pelo movimento demográfico de agricultores sulistas em direção ao norte impulsionado pela abertura de novas fronteiras agrícolas. Esta é uma explicação bastante incompleta e superficial quando se nega um fato histórico, qual seja, o importante papel desempenhado pela burguesia agrária, que acumulou capital durante os ciclos econômicos e depois reinvestiu parte dele na expansão e modernização agrícola, seja ampliando as propriedades, seja modernizando aquelas já existentes. Isto ocorreu em praticamente todas as regiões do país, com destaque para região Nordeste, que expandiu a agricultura concomitantemente à manutenção da cana-de-açúcar; para a região Sudeste, que expandiu sua agricultura durante e posteriormente ao auge do ciclo cafeeiro; e para a região Sul do país, cujos latifúndios pecuários tradicionais em muitas regiões deram lugar ao binômio trigo-soja, fato que logo se transformou no epicentro produtivo do modelo modernizante de agricultura.

O terceiro ponto diz respeito à afirmação de que na década de 1990 - frente às mudanças neoliberais que ocorreram na economia do país - se estabeleceu um novo padrão de financiamento da agricultura, com crescente participação dos recursos privados. Como não se mostra nenhuma evidência empírica, esta afirmação será contestada posteriormente quando forem apresentados os dados sobre financiamento da agricultura brasileira nos últimos 15 anos. Além disso, é destacada a expansão da importação de soja, especialmente por parte da China. De fato, esse é um processo em curso. Todavia, isso não pode ser considerado linearmente como um fator que desencadeou inovações tecnológicas neste produto e, consequentemente em toda agricultura brasileira. Os dados que serão apresentados posteriormente não comprovam esta argumentação, ao contrário, eles mostram que o fator preço do produto no mercado internacional é um dos principais indutores da expansão do volume total de soja produzido pelo país.

Da mesma forma, não podemos conceber que os resultados do processo modernizante em todo o território nacional decorrem apenas do período pós década de 1990. Ao contrário, cada fase deste processo mostrou seus resultados de maneira conclusiva, o que não permite creditar apenas "às mudanças institucionais da década de 1990 que corrigiram os bloqueios existentes" os resultados produtivos atuais, até mesmo porque o processo de liberalização e desregulamentação econômica que ocorreu no país foi generalizado, não afetando apenas o setor agrícola.

Dentre os resultados, os autores destacam a existência de uma nítida analogia entre o pro- 
cesso de transformação em curso no Brasil e aquele corrido nos EUA. Obviamente que tendo a revolução verde como pressuposto em ambos os países, é clara e evidente essa tendência. Todavia, a isso se denomina de "Via Norte-Americana" de desenvolvimento agrícola e não de "Via Argentina", como se qualificou em uma das teses. Além disso, devemos registrar que a heterogeneidade estrutural não é fato novo, ela apenas se manifesta de forma mais intensa no cenário atual, ressaltando-se, porém, que ela já estava imbricada neste modelo desde seus primórdios. Finalmente, deve-se registrar que é uma tendência histórica do modo de produção capitalista o processo de centralização, fato este que também já vem se revelando no setor agrícola, sendo as cadeias produtivas os agentes que comandarão esse movimento. Novamente registramos que este não é um fato novo, pois como mostraram Kageyama et al. (1990), ocorreu uma passagem do complexo rural para o complexo agroindustrial com uma integração cada vez maior da agricultura à indústria, culminando com a emergência de um novo padrão de acumulação de capital já a partir da década de 1980. Isso significou, segundo esses autores, um rompimento com a visão tradicional de se pensar a agricultura autonomamente em relação ao restante da economia nacional, uma vez que os complexos agroindustriais possuem determinações internas e externas que reduzem o poder explicativo de um único setor apenas.

\subsection{O padrão de acumulação da agricultura brasileira}

Na teoria econômica, padrão de acumulação de capital em qualquer atividade econômica tem uma definição conceitual bem precisa, inclusive com elementos explicativos claramente definidos. Por isso, não é possível sustentar a tese de "um novo padrão de acumulação da agricultura" como base na equivocada dicotomia de que a fonte de riqueza social antes era a terra e agora passou a ser o capital "em todas as suas modalidades", uma vez que a produção passou a depender cada vez mais de investimentos em infraestrutura, máquinas e tecnologia. Ora, como vimos anteriormente, a terra continua sendo um ativo financeiro de grande valor, portanto capital. Isto nos leva a concluir que essa distinção está muito mal fundamentada teoricamente, fato comum, aliás, a toda essa tese, uma vez que ela contém diversos equívocos analíticos que serão trados em breve.

O padrão de acumulação da agricultura brasileira seguiu uma trajetória histórica pautada pela fase inicial da modernização agrícola que se estendeu entre as décadas de 1960 e 1980. Esse período significou uma transformação na base técnica da produção agropecuária que tendeu a modificar cada vez mais uma forma natural de agricultura em um sistema produtivo cada vez mais dependente de máquinas, equipamentos e insumos químicos. Essa modernização, segundo Kageyama et al. (1990), culminou na própria industrialização da agricultura que explicitou um novo processo cada vez mais assentado no conhecimento e na possibilidade de reprodução artificial das condições naturais. Porém, isso não é apenas uma simples alteração decorrente da maior integração da agricultura com a indústria, mas também uma alteração crucial nas relações sociais de produção e nos próprios equipamentos de trabalho. Este processo que levou à formação dos Complexos Agroindustriais (CAIs) ainda em meados da década de 1980, alterou drasticamente o padrão de acumulação capitalista na agricultura anteriormente estabelecido. É justamente esse padrão que historicamente vem evoluindo e que pode estar adentrando em uma nova fase ainda a ser confirmada. Portanto, rigorosamente, não concordamos que há um novo padrão de acumulação, pois não podemos confundir uma nova forma de inserção da agricultura brasileira nos mercados (internos e externos) como sendo um novo padrão de acumulação de capital. Neste caso, as referências empíricas dos autores são bastante limitadas, conforme demonstraremos na sequência.

Em uma passagem sobre esse mesmo tema, os autores afirmam que "o arrendamento capita- 
lista... é, talvez, uma das sintomáticas expressões desse novo padrão..." (IBID, p. 110). Como os autores também afirmam que "suas proposições têm um inquestionável lastro empírico" ousaremos discordar dessa "inquestionabilidade". Para isso, utilizaremos informações de Hoffmann e Gomes Ney (2010) relativas à evolução da estrutura agrária e condição do produtor. Neste estudo, os autores organizaram uma série histórica com base nos dados do Censo Agropecuário (IBGE) entre 1975 e 2006 (último ano disponível). No primeiro ano da série (1975) existiam 569.882 arrendatários, sendo que dentre estes mais de 481 mil eram arrendatários situados no extrato de área de menos de 10 hectares, o que significava mais de $84 \%$ do total dessa condição de produtor. Já em 2006 essa categoria foi reduzida para 230.110, sendo que destes mais de 156 mil se situavam no extrato de até 10 hectares, o que em termos percentuais representava aproximadamente $70 \%$ dessa categoria de produtor. Paralelamente a isso, verifica-se que os arrendatários com extratos de área de 100 hectares ou mais eram menos de 7 mil em 1975 e continuavam sendo menos de 7 mil em 2006, inclusive com redução da área total utilizada por essa categoria de produtor. Isto nos permite concluir que a aludida expansão do arrendamento capitalista enquanto indicador de um novo padrão de acumulação não é real e carece de comprovação empírica.

Na sequência, os autores afirmam que o notável desempenho da agropecuária brasileira nas últimas três décadas se deve ao desempenho da produtividade dos fatores de produção, em especial do ambiente de inovações que difundiu novos conhecimentos e novos aparatos tecnológicos. Isso levou a uma expansão da produção total e, consequentemente, do saldo comercial da agropecuária, ao mesmo tempo em que "rebaixou o peso do fator terra". Essa argumentação, quando confrontada com a realidade, padece de sustentação, conforme argumentaremos com base em um conjunto de informações empíricas disponíveis. Não temos dúvida sobre a contribuição expressiva que a agropecuária brasileira vem apresentando nas relações comerciais do país ${ }^{7}$, que normalmente é explicitada em termos de valores monetários totais. Segundo dados MDIC/Secex (Sistema Alice), o total geral exportado pelo agronegócio em 2013 atingiu a marca de US\$ 94 bilhões, representando um acréscimo de quase $70 \%$ em relação ao valor total do ano de 2008. Mas o que chama atenção é a expressiva participação da produção vegetal neste montante global, equivalendo a $71 \%$ do montante no ano de 2013. Mais expressiva, ainda, é a participação das exportações de soja em grãos, que no ano de 2013 representou 34\% do valor total da produção vegetal exportada. Se a este produto for somada a participação das exportações de açúcar, chega-se a percentual de $53 \%$, ou seja, apenas a soja e o açúcar responderam por mais da metade do valor exportado na esfera vegetal. Isso demonstra o papel determinante que o item "soja em grãos" vem ocupado nas relações comerciais do país.

Em função disso, é importante observar o que vem ocorrendo na dinâmica produtiva desta cultura, até mesmo para estabelecer a interpretação dos fatos à luz de sua realidade. Para tanto, selecionamos algumas variáveis, cujo comportamento sustentará nossa argumentação no sentido de questionar aspectos fundamentais das " 7 Teses". A Figura 1 apresenta o comportamento da área plantada de soja, volume colhido e rendimento médio por hectare no intervalo entre 1996 e 2012, período de estabilização monetária também adotado como referência pelos autores das teses por nós questionadas.

Em relação à área plantada com soja, observa-se que ela quase triplicou ao longo do período considerado, passando de 10.3 milhões de hectares, em 1996, para 25.0 milhões de hectares, em 2012. Isso significou um aumento no percentual de expansão da área plantada da ordem de $141 \%$ no período considerado, ou então 2,5 vezes a área inicial. Já a produção total passou de 23 milhões de toneladas, em 1996, para mais de 65 milhões, em 2012, o que representou um acréscimo de

7. Mas esse não é um fato novo, pois desde a década de 1980 vem ocorrendo essa expressiva participação da produção agropecuária nas relações comerciais, fato que auxiliou significativamente na obtenção de superávits comerciais. 
Figura 1. Evolução da área plantada, da quantidade produzida e do rendimento médio da soja no Brasil entre 1996 e 2012

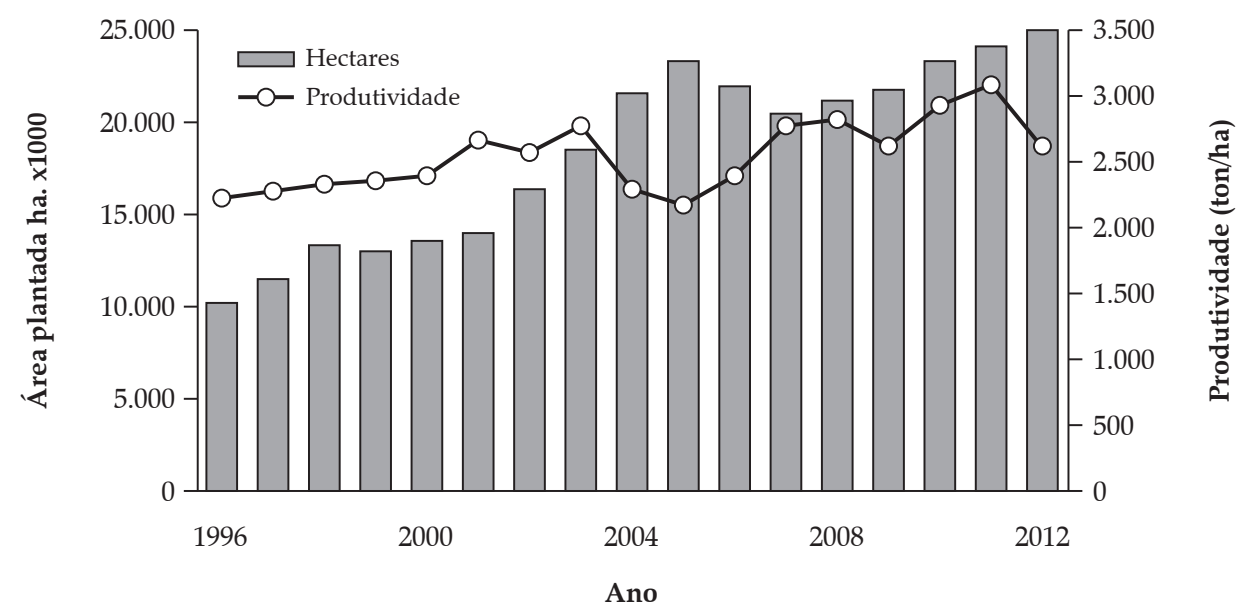

Fonte: IBGE/PAM, diversos anos. Elaboração: Tabajara Marcondes-Cepa/Epagri.

2,8 vezes ao total produzido no primeiro ano da série.

O rendimento médio por hectare não teve o mesmo comportamento, uma vez que variou apenas de $2.237 \mathrm{~kg} / \mathrm{ha}$, em 1996, para $2.624 \mathrm{kh} / \mathrm{ha}$, em 2012. Em termos percentuais isso representou um aumento de aproximadamente 15\%. Isso significou que a grande expansão da produção total da soja que ocorreu no país na última quinzena se deveu praticamente ao aumento da área plan- tada. Em grande medida, isso foi estimulado pelo cenário internacional favorável à referida cultura.

A Figura 2 apresenta a evolução anual dos preços da soja no mesmo período, verificando-se que entre 1996 e 2012 os preços da soja mais que triplicaram, passando de um patamar inferior a R\$ 20,00 a saca no ano de 1996 para mais de R\$ 70,00 a saca em 2012. Entendemos que esse comportamento extremamente positivo dos preços, aliado a uma conjuntura internacional favorável

Figura 2. Evolução dos preços da saca de soja entre 1996 e 2012

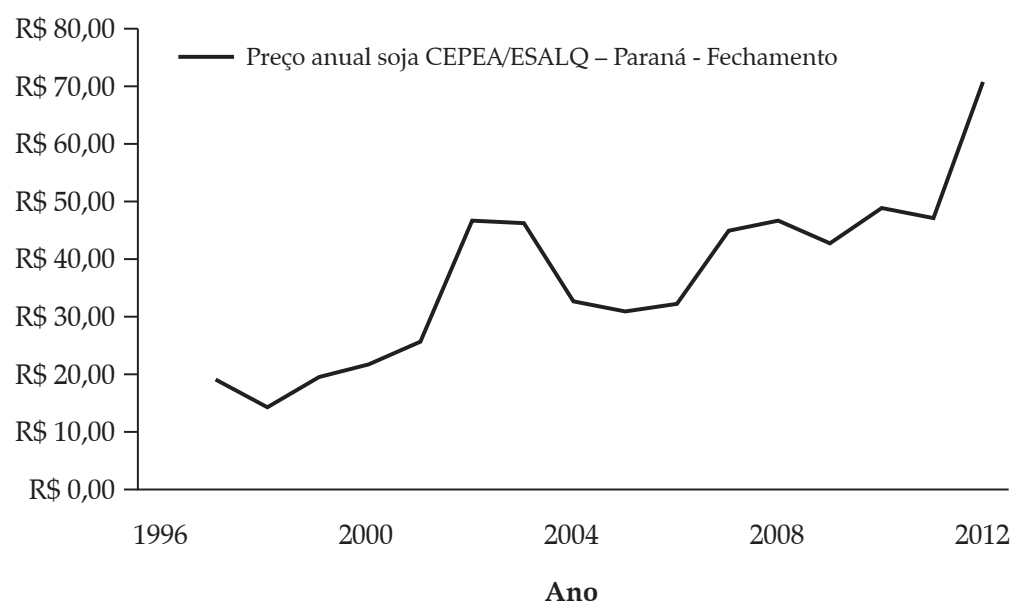

Fonte: Cepea/Esalq-USP. 
dada pelo aumento da demanda desse produto, especialmente em função das crescentes importações chinesas, foram decisivos para estabelecer a expansão tão expressiva da produção global de soja no Brasil.

Em função disso, questiona-se fortemente a argumentação central apresentada pelos autores, cuja tese afirma que no padrão de acumulação atual a produção de riqueza social não está mais vinculada à terra, mas sim às tecnologias modernas (máquinas, equipamentos e insumos agropecuários, etc.) e ao capital humano. E de forma mais contundente, rejeitamos a tese de que o peso do fator terra não tem mais importância no contexto atual. Ora, se isto fosse verdadeiro, não poderiam ter sido incorporados ao processo produtivo mais de 15 milhões de hectares para cultivo da soja em apenas quinze anos.

Não são negados os avanços tecnológicos que foram incorporados aos diversos sistemas produtivos do setor agropecuário. Todavia, isso por si só não pode ser tomado como explicação exclusiva para se analisar o contexto atual. Perfazendo esse caminho, os argumentos presentes nas "7 Teses" saem do rigor acadêmico e descambam para o debate ideológico. E isso fica mais evidente no tratamento dispensado à questão agrária brasileira, que continua não resolvida.

\subsection{A negação da questão agrária e da reforma agrária}

Ao discutir esse assunto temos a nítida sensação de estarmos diante de um filme que já assistimos. Atualmente, sob o desígnio da grande participação do agronegócio nas relações comerciais, diversas matizes de analistas procuram sistematicamente rebaixar a questão agrária, utilizando-se dos mais variados tipos de argumentação. No passado recente a linha argumentativa era muito semelhante, sendo apenas o uso de indicador distinto. Em períodos anteriores era comum se utilizar o argumento das famosas "supersafras" para simbolizar o apogeu do processo modernizante sobre todas as demais formas de produção existentes no meio rural do país e, consequentemente, para negar qualquer possibilidade de alteração da estrutura agrária do país.

Fazendo uma distinção necessária entre o significado da questão agrícola e da questão agrária, percebe-se claramente que os principais indicadores relativos à última acabaram sendo agravados pelo próprio equacionamento de alguns indicadores da primeira, o que implica dizer que a questão agrária brasileira permanece sem solução. Esse fato por si só recoloca o tema da reforma agrária continuamente na agenda política nacional, por mais que alguns teimam em tentar "rebaixá-lo" ou "apagá-lo" da história do país.

Neste sentido, chama atenção diversas passagens em que os autores fazem afirmações textuais sem haver uma preocupação rigorosa entre as mesmas e suas conexões com a realidade. Assim, no início dessa tese específica afirma-se categoricamente que "o último meio século desmentiu diversas antevisões: da exacerbação da questão agrária...às supostas tendências da concentração da propriedade fundiária e, mais ainda, as teses sobre o campesinato" (IBID, p. 115).

Quanto às teses sobre o campesinato, consideramos que as explicações de Costa (2013) são suficientes para refutar a argumentação evocada pelos autores das "7 Teses". Isto porque

as teses não admitem a diversidade estrutural substantiva, de natureza e essência, nem especificidade nas razões dos agentes que a materializam, do mesmo modo que não problematizam o sentido de suas relações políticas e territoriais (COSTA, 2013, p. 48).

Além disso, esse autor afirma também que

sobre esse universo rural de base camponesa, só acessível como realidades territorializadas, se sabe muito pouco e a manipulação de caricaturas estatísticas não supre as abissais lacunas (COSTA, 2013, p. 52-53).

Quanto à questão da concentração da propriedade fundiária, observamos que a realidade, às vezes, é mais teimosa que determinadas teses. Assim, verifica-se que entre 1975 e 2006 o número 
de estabelecimento correlacionado aos estratos de área manteve a trajetória já amplamente documentada sobre a crescente concentração da propriedade fundiária no país. Com isso, o Censo Agropecuário de 2006 registrou que os estabelecimentos com até 10 hectares representavam mais de $50 \%$ do total dos estabelecimentos, porém detendo apenas $2,4 \%$ da área total. Já os estabelecimentos com 100 ou mais hectares representavam menos de $10 \%$ do total de estabelecimentos agropecuários do país, porém detendo $78,6 \%$ da área total.

Desta forma, podemos dizer que existe uma desigualdade fundiária alta quando um pequeno número de estabelecimentos ocupa uma grande parte da área total. E essa desigualdade é medida pelo Índice de Gini, que passou de 0,839, em 1960, para 0,856 no ano de 2006. Ora, essa é uma concentração fundiária elevada, fazendo com que o Brasil figure entre o grupo de países do mundo que apresenta os maiores índices de concentração de terra.

Com isso,

não obstante evidências óbvias de que a posse, propriedade e uso da terra (recurso natural) e sua concentração são hoje uma estratégia essencial ao estilo de acumulação de capital, que se reforçou no Brasil na última década, os arautos dessa economia (do agronegócio), com complacência dos desinformados, negam a situação real para justificar seus interesses (DELGADO, 2013, p. 61).

Ainda neste ponto os autores das "7 Teses", ao recuperarem parte do debate passado sobre a questão agrária brasileira, não fazem menção a dois aspectos centrais: a concentração da propriedade da terra e o problema das relações de trabalho no campo. Parece que se esquecem disso para afirmar dois argumentos básicos: a evolução da agricultura moderna reduziu o papel dos "produtores de menor porte", cujo nível de renda não tem mais nenhum significado para o dinamismo do mercado interno; e em razão disso afirmam que não há mais demanda social para a reforma agrária.
Quanto ao primeiro argumento, entendemos ser temerário discutir o papel social dos produtores de menor porte (na verdade agricultores familiares) unicamente a partir do nível de renda e correlacionar isso com a dinâmica do mercado interno. Esse mercado, totalmente distinto daquele dos anos de 1960 por razões óbvias, é abastecido tanto pela produção interna como externa. Todavia, não podemos ignorar o papel relevante dos agricultores familiares na produção de alimentos básicos que compõem a cesta alimentar da população brasileira. Dados do Censo Agropecuário de 2006 ressaltam esse aspecto, ao detectar que a maioria da produção alimentar destinada à população (e não às exportações) provém do setor produtivo familiar. Negar isso significa a negação de uma realidade complexa, porém efetiva em termos da produção alimentar do país ${ }^{8}$.

De um modo geral, pode-se dizer que esta visão sobre o universo dos produtores rurais está muito atrelada à concepção de desenvolvimento que se adota nas respectivas análises. Neste sentido, não resta dúvidas de que a perspectiva analítica das " 7 Teses" não está discutindo desenvolvimento rural, mas sim desenvolvimento agrícola, uma vez que suas premissas são área plantada, produção, produtividade, etc. Ou seja, o desenvolvimento rural pensado a partir do comportamento de indicadores específicos do setor agrícola, concepção que obrigatoriamente leva à conclusão da supremacia da "agricultura moderna" em relação às demais formas de produção rural ${ }^{9}$.

8. Os dados do Censo Agropecuário de 2006 revelam que a grande maioria da produção de produtos alimentares de origem vegetal (milho, arroz, feijão, mandioca e hortifrutigranjeiros) e também de origem animal (leite, ovos, frangos, etc.) tem origem na agricultura familiar. Negar isso é demonstrar exatamente o oposto do que pretendem as " 7 Teses", ou seja, ter qualquer fundamentação empírica.

9. A concepção de desenvolvimento rural engloba um conjunto de outros indicadores para além do desempenho específico das atividades agrícolas, com destaque para indicadores relativos à concentração dos meios de produção, à geração e distribuição da renda, à qualidade de vida das pessoas, ao acesso aos mercados, etc. Isso significa uma teia bem mais complexa que se desenvolve, em muitos casos, paralelamente ao próprio desenvolvimento da agricultura, porém com interações mútuas. 
O argumento de que não há mais demanda social para a reforma agrária explicita claramente a concepção anterior de desenvolvimento. Todavia, uma análise desideologizada do assunto permite a percepção da existência de um universo bem distinto daquele apresentado pelas " 7 Teses". Estudo de Graziano da Silva e Del Grossi (2000) sobre as famílias rurais no Brasil revelou a existência de aproximadamente três milhões de famílias classificadas pelos autores como sendo de "Trabalhadores Sem Terra", paralelamente a um grupo semelhante de famílias que já estavam sendo atendidas pelo Pronaf. A conclusão do trabalho desses autores revelou que havia uma relativa estabilidade neste último grupo, enquanto o primeiro grupo tendia a crescer. E isso mostrava que o problema transcendia a simples doação de um pequeno pedaço de terra a essas famílias que se encontravam na situação de sem terra, sendo necessária uma política pública efetiva de desenvolvimento rural.

Ainda em termos de demandas sociais pela reforma agrária deve-se registrar que a forma mais visível da existência dessa demanda se explicita nos acampamentos de trabalhadores rurais que há dezenas de anos tomam conta de várias regiões do país. Atualmente, dados extraoficiais revelam que aproximadamente 100 mil famílias de trabalhadores sem terra estão acampados pelo país, sendo a maioria delas na região Nordeste. Se a este contingente for somada a imensa quantidade de agricultores familiares com pouca terra (menos de 5 hectares), chega-se a um número expressivo de mais de 3 milhões de famílias de sem-terra, o que confirma os prognósticos dos autores anteriormente citados.

Além desses argumentos, os autores das "7 Teses" afirmam textualmente que

diferentemente do passado, a incorporação de novas terras explica pouco o crescimento da produção, e o dinamismo da agropecuária decorre principalmente de investimentos e da intensificação tecnológica (IBID, p. 116).

Em termos da "agricultura moderna", essa é mais uma afirmação que carece de sustenta- ção empírica. Como mostramos no caso da soja, produto símbolo da evocada modernidade, a expansão de área em duas décadas quase triplicou, enquanto que a produtividade passou de $2.030 \mathrm{~kg} / \mathrm{ha}$, em 1992, para $2.624 \mathrm{~kg} / \mathrm{ha}$, em 2012, o que significou um crescimento de menos de $20 \%$. Outra informação que contraria o argumento dos autores foi revelada pelo último Censo Agropecuário (2006), quando ficou constatado que entre 1995-96 e 2006 as "áreas de lavouras" tiveram um crescimento de mais de $83 \%$, o que significou a incorporação ao processo produtivo agrícola de aproximadamente 42 milhões de hectares de terras no período intercensitário.

Portanto, é necessário reconhecer que a grande expansão da produção agropecuária do país, especialmente nos últimos 20 anos, guarda uma relação direta com a incorporação de novas terras ao processo produtivo agrícola, sendo bem menos expressivos os efeitos da intensificação tecnológica na produção agrícola agregada. Os dados disponíveis para a grande maioria das culturas comprovam esse fato, assim como a própria composição das exportações do país, cujo mix exportador é dominado atualmente por produtos primários com baixíssimo grau de intensidade tecnológica.

Em síntese, dados e informações empíricas apresentadas neste item são suficientes para demonstrar a inconsistência de mais uma dessas teses que, longe da inquestionabilidade empírica, enveredam-se fortemente para a esfera de um debate meramente ideológico que privilegia a negação pela negação.

\subsection{Sobre o papel do Estado no desenvolvimento agrícola}

Desde o pós-guerra o Estado vem tendo um papel decisivo no desenvolvimento agrícola brasileiro. É indiscutível que a "modernização agrícola" do país só ocorreu devido à ação estatal. Esse é um processo que já foi longamente estudado pela literatura especializada, não cabendo neste momento um retorno aos argumentos centrais desse debate. Porém, diante das formulações 
específicas dos autores das "7 Teses" sobre este assunto, cabe aqui um conjunto de críticas fundamentadas à luz do contexto econômico rural atual.

Tomando como referência a década de 1990, os autores das referidas teses afirmam resumidamente que a partir dessa época ocorreu uma saída "à francesa" da intervenção do Estado na economia rural, fato este comprovado pela redução dos gastos públicos na agricultura. E mais, que agora são os agentes privados os principais atores responsáveis pelo desenvolvimento agrícola do país. Finalizam essa parte fazendo uma crítica à ação atual do Estado devido à leitura equivocada que tem sido feita em relação às transformações em curso e concluem que não é mais necessária nenhuma ação estatal porque os desafios são tão complexos que transcendem as próprias possibilidades desse mesmo Estado.

Diante desse conjunto de afirmações, que mais se parecem com a cantilena ideológica liberal dos anos de 1990, é preciso recompor os fatos em seu devido lugar. Para isso, é necessário entender corretamente o que ocorreu na década de 1990 e as alterações em curso no presente, que tiveram início a partir de 2003. Para tanto, serão utilizadas informações oficiais para contestar, de maneira incisiva, os equívocos contidos nesta que é considerada pelos próprios autores como "uma tese crucial" ${ }^{\prime \prime}$.

Em primeiro lugar, é preciso qualificar melhor as "reformas institucionais" da década de 1990 visando entender corretamente seu sentido, bem como seus impactos sobre o setor agropecuário brasileiro. Registra-se que na referida década esteve em voga a chamada política do "Novo Mundo Rural", a qual contemplava as estratégias definidas pelo Banco Mundial, especialmente para a América Latina. Tal estratégia,

10. Chama atenção, todavia, a superficialidade dessa tese, uma vez que ela se sustenta no argumento único de que houve redução dos gastos públicos com a agricultura. Não se faz uma discussão mínima sobre as principais mudanças de ordem institucional que ocorreram na década de 1990, bem como não se faz menção sequer ao movimento em sentido oposto que ocorreu a partir de 2003, o qual tem impactos diretos sobre o argumento central dessa tese. embrenhada pelos princípios do "Consenso de Washington", definia claramente a desregulamentação das atividades econômicas agrícolas e determinava novas formas de regulação institucional que dessem maior poder aos agentes privados para que os mercados fossem capazes de reorganizar os setores produtivos e determinar o ritmo do crescimento econômico setorial ${ }^{11}$.

Sem a pretensão de esgotar o assunto, vamos fazer uma breve síntese das principais medidas adotadas na direção antes mencionada ${ }^{12}$. Inicialmente, deve-se registrar que a forma de intervenção do Estado brasileiro na década de 1990 cumpriu integralmente os ditames gerais da ordem econômica mundial, mesmo que a oferta de crédito agrícola tenha sido reduzida em alguns períodos em função da crise econômica. Naquele período foi promulgada a Lei de Patentes, a Lei de Cultivares, a Lei 8.661/93 (que descontava 8\% do imposto de renda devido para aplicação em pesquisa), bem como a adesão às novas regras da OMC e ao acordo TRIPS (Trade Related Aspects of Intellectual Property Rights). Isso tudo efetivamente se traduziu em uma forte intervenção do Estado em favor do capital produtivo nacional e internacional, cujo epicentro são os grandes conglomerados da indústria química e das multinacionais que dominam o mercado mundial de sementes. Nesta lógica, registra-se, ainda, a reclassificação de produtos agrotóxicos, permitindo o uso no Brasil de muitos produtos com toxidade elevada que são proibidos em várias partes do mundo ${ }^{13}$.

Ainda na década de 1990 foram adotadas diversas medidas econômicas de caráter interno,

11. Os autores das "7 Teses" relatam esse processo como sendo o "divisor de águas da história rural do país", o qual promoveu a hegemonia da "agricultura moderna". Outros autores afiliados a essa mesma corrente de pensamento qualificam como "hegemonia do agronegócio".

12. Para maiores esclarecimentos, consulte-se Teixeira (2013).

13. Segundo Teixeira (2003), durante o Governo FHC, atos do Ministério da Agricultura - sem autoridade para tal - elevaram em 50 vezes o limite de glifosato permitido nos grãos de soja. Essa medida foi crucial para a aprovação posterior dos produtos transgênicos (Lei de Biossegurança), além de tornar o Brasil o país com maior volume de aplicação de venenos na agricultura mundial. 
porém com importantes efeitos sobre o comportamento geral do setor agropecuário. Destaca-se, neste caso, a Lei Kandir, que compensa perdas de competitividade decorrentes da política cambial. Tudo isso é compensado com recursos diretos e indiretos do Estado. Mesmo com a mudança do regime cambial (1999), essa lei foi mantida, elevando os custos da união e dos estados em relação aos setores exportadores. Além disso, duas outras medidas importantes devem ser mencionadas. Por um lado, entraram em funcionamento no início da década de 1990, os Fundos Constitucionais para financiamento do desenvolvimento das regiões Norte, Nordeste e Centro-Oeste, previstos na Constituição de 1988. Esses fundos destinaram volumes significativos de recursos do Estado nessas regiões, sendo parte expressiva desses recursos utilizada pela agricultura. Por outro, desde 1995 vêm sendo prorrogadas, repactuadas e anistiadas dívidas agrícolas junto aos três principais bancos operadores do Sistema Nacional de Crédito Rural (BB, BNE e Basa), gerando custos elevados ao Tesouro Nacional. Apenas para se ter uma ideia da dimensão disso, registra-se que no ano de 2011 o Ministério da Fazenda informou que essa dívida atingiu a cifra de $\mathrm{R} \$ 149,2$ bilhões, sendo a grande maioria dela oriunda de operações creditícias do setor patronal e empresarial agrícola do país ${ }^{14}$.

Também deve merecer uma nota especial a criação, em 1996, do Programa Nacional de Fortalecimento da Agricultura Familiar (Pronaf) que, pela primeira vez na história, destinou recursos públicos específicos do sistema de crédito para a categoria de agricultores familiares, os quais tradicionalmente eram excluídos do sistema público de financiamento das atividades agrícolas, embora representassem mais de $80 \%$ dos estabelecimentos agropecuários do país.

Esse movimento institucional teve continuidade na primeira década do século XXI (Governo Lula), cujas ações, além de fortalecer as estraté-

14. Segundo Teixeira (2003), na década de 1990 foram estatizadas até mesmo dívidas contratadas por grandes agricultores junto às grandes empresas que controlam os insumos e a comercialização. gias mercadológicas anteriormente citadas, também se voltaram para a recomposição do apoio, por parte do Estado brasileiro, ao setor agropecuário. Sem dúvida alguma, esse duplo movimento do Governo Lula foi decisivo para se entender a dita "hegemonia do agronegócio", que está sendo cantada em prosa atualmente, como se ela fosse obra do acaso.

Do ponto de vista institucional legal, merecem ser citadas a aprovação da liberação dos Organismos Geneticamente Modificados (OGMs) na agricultura (Lei 11.105, de 2005) e a aprovação do novo Código Florestal, que flexibiliza as normas ambientais. Além disso, devem ser mencionadas as ações do Programa Terra Legal, que permitem a expansão da fronteira agrícola e pecuária na região Amazônica, bem como muitas obras do Programa de Aceleração do Crescimento (PAC) que visam disponibilizar energia e sistemas de transportes para beneficiar diretamente o setor agropecuário do país.

Em termos específicos do crédito rural, diferentemente do afirmado pelos autores das "7 Teses", o Estado voltou a atuar de forma decisiva após 2003, conforme dados e informações oficiais que serão sistematizados na sequência. Em termos agregados, recursos públicos destinados ao financiamento da agricultura empresarial atingiram uma média anual de $\mathrm{R} \$ 35$ bilhões entre 1995 e 2002, subindo para uma média de R\$ 79 bilhões entre 2003 e $2012^{15}$. Além disso, devem-se ser registrados mais dois dispêndios fundamentais do Estado brasileiro em favor da agricultura empresarial (agronegócio). Por um lado, os gastos tributários do Estado (renúncia fiscal) com a agricultura empresarial passaram de $\mathrm{R} \$ 684$ milhões, em 2003, para mais de R\$ 12 bilhões em 2013, conforme informações da Secretaria da Receita Federal. Por outro, menciona-se a disponibilização de bilhões de reais na última década, via BNDES com aporte de recursos do Tesouro Nacional, às empresas do agronegócio, especialmente nos setores de carnes e sucroalcooleiro.

15. Dados analisados por Teixeira (2013) a partir de informações disponibilizadas pelo SNCR. 
Tal ação visa à construção de empresas nacionais com capacidade de operar e competir no mercado mundial. Aqui não se está discutindo essa estratégia, apenas registrando que tudo isso está sendo feito com recursos públicos, via Tesouro Nacional. Parece que esses fatos empíricos reais não têm grande importância, sendo sequer mencionados pela narrativa dos defensores do "agronegócio moderno".

Ainda sobre a disponibilização de recursos públicos para a agropecuária brasileira, sabe-se que desde o final dos anos de 1990 a cada ano o Governo Federal anuncia, tanto o Plano Safra da Agricultura Familiar como o Plano Agrícola e Pecuário (PAP), com recursos e ações destinadas especificamente à agricultura patronal e familiar. Ambas as ações visam atender demandas específicas de cada um desses macro setores e, ao mesmo tempo, ampliar a produção agropecuária do país.

Deste modo, observa-se uma liberação crescente de recursos públicos para o setor agropecuário. Para se ter uma ideia da dimensão da ação governamental basta informar os dados recentes. Em relação ao PAP, nota-se que na safra 2011/2012 foram disponibilizados R\$ 107,21 bilhões, valor que passou para $\mathrm{R} \$ 115,2$ bilhões na safra 2012/2013 e chegou a R\$ 136 bilhões na safra de $2013 / 2014$. Isso tudo a uma taxa de juros anual que varia entre 3,5\% a 5,5\%. Já o Plano Safra da Agricultura Familiar disponibilizou para a safra 2013/2014 a importância de R\$ 39 bilhões ${ }^{16}$.

Isso significa, segundo Delgado (2013,p.62), que "a economia do agronegócio requer uma ação consertada do Estado, sem o que essa estrutura não existiria, na acepção de estratégia de economia política. Neste sentido, a construção histórica da atual economia do agronegócio vem lá da modernização conservadora...e forja-se a acumulação de capital no âmbito desses setores amalgamados pelo dinheiro público -agricultura, sistema de crédito e mercado de terras - como novo estilo do capitalismo agrário".

16. Dados organizados por Tabajara Marcondes, técnico do Cepa/Epagri, com base no anuário estatístico do crédito rural.

\section{Considerações finais}

O ponto de partida desse ensaio foi apresentar uma visão crítica sobre as "teses" recentes que foram objeto de análise no artigo, visando efetivamente dar consistência e pluralidade a um debate que julgamos de extrema importância para o meio rural e, particularmente, para o próprio país.

Nossa percepção inicial foge aos padrões analíticos das teses propostas, uma vez que não nos fixamos a apenas um único indicador: a expansão setorial da agricultura brasileira. Ao contrário, entendemos que o contexto atual nos obriga a realizar um debate sobre o desenvolvimento rural do país numa perspectiva multifacetária e multidimensional que moldou a trajetória desse espaço, especialmente depois do pós-guerra. Sem lançar mão dessa visão, entendemos que se estará cometendo muitos equívocos e apresentando apenas "pacotes ideológicos", e não teses fundamentadas na realidade agrícola e agrária do país.

Isso fica patente em várias passagens já comentadas sobre as "7 Teses", especialmente quando se discutem os temas do padrão da acumulação, da questão agrária e do papel do Estado. Lacunas interpretativas ficaram visíveis, sendo que em muitas passagens fenômenos distintos são tratados como se fossem semelhantes, particularmente quando se faz uma interpretação linear de desenvolvimento da agricultura associada ao desenvolvimento rural, sem as devidas mediações.

Além disso, apontamos ao longo do texto que diversas contradições ficaram evidentes quando se analisa o artigo "7 Teses". Dentre essas contradições são destacadas a interpretação limitada sobre a relação entre o processo de modernização e o movimento demográfico ocorrido no país; a leitura e interpretação do papel do Estado a partir da década de 1990; a exemplificação da existência de um novo padrão de acumulação com base em afirmações que não têm qualquer aferição empírica; a negação do papel do Estado no apoio ao desenvolvimento rural; e a tradicional leitura equivocada da estrutura agrária do país. 
Como as teses criticadas apresentam uma amplitude e diversas dimensões analíticas, e considerando o espaço previamente delimitado para este ensaio, nos limitamos a apresentar uma análise crítica em quatro pontos que consideramos essenciais, uma vez que muitas das autodenominadas "teses" sequer podem assim ser chamadas porque são meras interpretações e análises de determinados assuntos para se afirmar, em grande medida, a hegemonia econômica da "agricultura moderna" sobre todas as demais formas de produção existentes no espaço rural. É exatamente nestas passagens que a ideologia se sobrepõe às boas teorias, fazendo com que a história da trajetória recente das transformações rurais tenha apenas uma interpretação e um único resultado visível. Aqui aparece o recurso ao "discurso de autoridade" dos autores, afinal as teses apresentadas são "inquestionáveis" porque têm ampla base empírica.

Ora, como vimos em apenas um único exemplo - expansão da produção de soja no país nas duas últimas décadas - todo o debate sobre a perda da importância da terra e da relevância da produtividade não se sustentam empiricamente. Ao contrário do afirmado pelos autores, o que levou a essa excepcional produção agropecuária do país foram dois fatores que se somam: a enorme incorporação de novas terras destinadas a este tipo de cultivo e o movimento extremamente positivo dos preços do produto no mercado internacional. Como vimos, a produtividade da referida cultura praticamente se manteve nos mesmos patamares, comparativamente à expansão expressiva da área plantada.

Há, ainda, um conjunto de outros argumentos presente no artigo "7 Teses" que sequer foram objeto de crítica em nossa análise, mas que igualmente poderiam ser facilmente questionados com base em informações empíricas. Além disso, o uso do valor bruto da produção para afirmar a hegemonia de um determinado setor necessita ser refutada por uma razão óbvia: desconsidera-se a questão relevante do consumo intermediário no processo de produção. Essa opção metodológica (inconsistente) tem implicação direta sobre alguns resultados apresentados para refutar a importância de outras formas de produção existentes no meio rural.

Por isso, entendemos que as críticas que apresentamos almejam contribuir com um debate que consideramos relevante para o país. Porém, alertamos que o mesmo não pode ser contaminado pelo viés ideológico e desvirtuado da realidade complexa existente no meio rural brasileiro. Acreditamos que se livrando desses atributos será bem mais produtivo debater e propor soluções efetivas para um verdadeiro desenvolvimento rural, sem hegemonias e sem exclusões.

\section{Referências bibliográficas}

BUAINAIN, A. M. et al. Sete teses sobre o mundo rural brasileiro. Revista de Política Agrícola, v. 22, n. 2, p. 105121, 2013.

CENTRO DE GSTÃO E ESTUDOS ESTRATÉGICOS. A pequena produção rural e as tendências do desenvolvimento agrário brasileiro: ganhar tempo é possível? Brasília: CGEE, 2013.

COSTA, F. A. Sete teses sobre o mundo rural brasileiro: antíteses. Revista da ABRA, edição especial, jul. 2013.

DELGADO, G. Do capital financeiro na agricultura à economia do Agronegócio. Brasília: IPEA, 2012.

. Economia do agronegócio (anos 2000) como pacto do poder com os donos da terra. Reforma Agrária, edição especial, jul. 2013.

FRANÇA, C. G. et al. O Censo Agropecuário 2006 e a agricultura familiar no Brasil. Brasília: MDA-NEAD, 2009.

GASQUES, J. G. et al. Agricultura Brasileira: desempenho, desafios e perspectivas. Brasília: IPEA, 2010, 298p.

GRAZIANO DA SILVA, J. e DEL GROSSI, M. E. Ocupação nas famílias agrícolas e rurais no Brasil: 19921997. In: CAMPANHOLA, C. e GRAZIANO DA SILVA, J. (Org.). O novo rural brasileiro: uma análise nacional e regional. Jaguariúna (SP): Embrapa, 2000.

GRAZIANO DA SILVA, J. O que é a questão agrária. São Paulo: Brasiliense, 1985. A nova dinâmica da agricultura brasileira. Campinas: UNICAMP, 1996. 
HOFFMANN, R. e GOMES NEY, M. Evolução recente da estrutura fundiária e propriedade rural no Brasil. In: GASQUES, J. G. et al. (Orgs.). A agricultura brasileira: desempenho, desafios e perspectivas. Brasília: IPEA, 2010, 298p.

HOFFMANN, R. e GOMES NEY, M. Estrutura fundiária e propriedade agrícola no Brasil, grandes regiões e unidades da federação. Brasília, MDA, 2010.

KAGEYAMA, A. et al. O novo padrão agrícola brasileiro: do complexo rural aos complexos agroindustriais. In: DELGADO, G. et al. (Org.). Agricultura e Politicas Públicas. Brasília: IPEA, 1990 (Relatório n. 127).
MATTEI, L. A evolução do emprego agrícola no Brasil. São Paulo: Coleção ABET -Mercado de Trabalho, 1998, v. 1, 112p.

MINISTÉRIO DO DESENVOLVIMENTO AGRÁRIO. Brasil Rural em Debate: coletânea de artigos. Brasília: CONDRAF-MDA, 2010.

NAVARRO, Z. Meio século de transformações do mundo rural brasileiro e a ação governamental. Revista de Política Agrícola, ano XIX, edição especial, jul. 2010, p. 107-118.

TEIXEIRA, G. A sustentação política e econômica do agronegócio no Brasil. Reforma Agrária, edição especial, jul. 2013. 
